\title{
Self-Reported Opportunistic Screening Mammography in Austria - 2005 vs. 1995
}

\author{
Christian Vutuc $^{\mathrm{a}}$ Thomas Waldhoer $^{\mathrm{a}}$ Paul Sevelda ${ }^{\mathrm{b}, \mathrm{c}} \quad$ Michael Micksche $^{\mathrm{b}, \mathrm{d}}$ Gerald Haidinger $^{\mathrm{a}}$ \\ ${ }^{a}$ Department of Epidemiology, Center of Public Health, Medical University of Vienna, \\ ${ }^{\mathrm{b}}$ Austrian Cancer Society, \\ c Department of Gynecology and Obstetrics, Lainz Hospital, Vienna, \\ ${ }^{d}$ Department of Internal Medicine I, Institute of Cancer Research, Medical University of Vienna, Austria
}

\section{Key Words}

Austria - Mammography · Breast cancer - Screening

\section{Summary}

Background: The prevalence of self-reported participation in opportunistic screening mammography in Austrian women aged $40-79$ years in the year 2005 is reported and compared with the results of a similar investigation from 1995. Methods: In a representative populationbased cross-sectional study, 552 women were asked about their usage of opportunistic screening mammography (number and time interval). Results: Overall the prevalence of self-reported opportunistic breast cancer screening was $81.9 \%$ (95\% confidence interval, $95 \% \mathrm{Cl}$ : 78.4-85.5). The highest prevalence was observed in the age group 60-69 years with $87.6 \%$ (95\% Cl: 81.5-92.2), the lowest prevalence in the age group 70-79 years with 69.6\% (95\% Cl: 57.3-80.0). Compared with 1995, the screening prevalence showed significant increases in the total group as well as in the single age groups. Conclusion: Opportunistic screening mammography is well accepted in Austria, with an increasing trend of regular utilization.

\section{Introduction}

Breast cancer is the leading cause of cancer death among women in Austria [1]. Like in many other countries mortality has decreased since the early 90s, commonly explained by the introduction of mammography screening for early detection of breast cancer in asymptomatic women and by improved therapeutic regimes [1-3]. In fact, opportunistic

\author{
Schlüsselwörter \\ Österreich · Mammografie - Mammakarzinom · \\ Screening
}

\section{Zusammenfassung}

Hintergrund: Wir berichten über die Prävalenz der Inanspruchnahme von opportunistischen Screening-Mammografien bei 40-79-jährigen Frauen in Österreich im Jahr 2005 und vergleichen die Angaben mit den Ergebnissen einer - nach identischen Methoden - im Jahr 1995 durchgeführten Querschnittserhebung. Methoden: Befragung einer für Österreich repräsentativen Stichprobe von 552 Frauen. Ergebnisse: Insgesamt haben 81,9\% der Befragten (95\%-Konfidenzintervall, 95\% Cl: 78,4-85,5) schon einmal eine opportunistische Screening-Mammografie in Anspruch genommen. Die höchste Prävalenz zeigte sich in der Gruppe der 60-69-jährigen Frauen (87,6\%, 95\% Cl: 81,5-92,2), die niedrigste Prävalenz bei den 70-79-jährigen Frauen (69,6\%, 95\% Cl: 57,3-80,0). Gegenüber 1995 ist die Prävalenz um 23,6\% gestiegen. Schlussfolgerung: Die opportunistische Screening-Mammografie ist in Österreich gut etabliert, mit zunehmender Akzeptanz in den letzten 10 Jahren.

\begin{tabular}{ll}
\hline KARGER & @ 2007 S. Karger GmbH, Freiburg \\
$\begin{array}{l}\text { Fax }+497614520714 \\
\begin{array}{l}\text { E-mail Information@Karger.de } \\
\text { www.karger.com }\end{array}\end{array}$ & $\begin{array}{l}\text { Accessible online at: } \\
\text { www.karger.com/brc }\end{array}$ \\
&
\end{tabular}

screening in Austria already started in 1974, when an annual health checkup, recommended for all persons aged $\geq 40$ years, available free of charge and funded by the General Health Insurance Plan (compulsory insurance system in Austria), was introduced [4]. To screen in age groups younger than 50 years usually is not recommended internationally, however, many women between 40 and 50 years of age could profit also [5]. 
In 1995, for the first time in Austria, the prevalence of self-reported participation in opportunistic screening mammography in women aged 40-79 years (the age range that has been targeted for opportunistic mass screening since 1980) was evaluated in a cross-sectional study [4]. In this paper we report the results of a repeat of this survey in 2005 , using the same methods like in 1995.

\section{Material and Methods}

The data analyzed were extracted from the population-based cross-sectional study 'Attitudes towards Cancer' conducted in August 2005, which covered all parts of Austria (population: 8.17 million, 6.85 million $\geq 15$ years of age, 1.92 million women aged 40-79 years). The aim of this study was to survey knowledge, attitudes, and behavior of the Austrian population with respect to various aspects of cancer. It was a repeat of a crosssectional study conducted in 1995 using the same selection criteria, sample size, methods, and questionnaire [4, 6-8].

In cooperation with a public opinion survey institute, a quota sample of 2,400 Austrians aged $\geq 15$ years was selected. The sample comprised $0.04 \%$ of the population $\geq 15$ years of age and was representative in terms of age, sex, occupational status, and area of residence (source: population census 2001). The respondents were visited in their homes by 208 trained interviewers. The interview was face to face, using an anonymous standardized questionnaire. Of the 2,400 planned interviews a quota of $83.3 \%$ could be realized; 400 persons were not at home or refused interview. The remaining sample of exactly 2,000 persons (960 men and 1,040 women) meets the inclusion criteria regarding representativeness. For validation purposes, $30 \%$ of the interviews were reexamined by telephone, and no significant differences to the original face-to-face interview were found The sample of respondents was weighted by age ('post-stratified') to the Austrian census population 2001 .

The analysis of prevalence of self-reported participation in opportunistic screening mammography was restricted to women aged 40-79 years, thus 552 women formed the study group for this analysis. The questionnaire explicitly asked for the screening procedure in asymptomatic women and not for diagnostic examination. Women were asked if they ever had heard of early detection of breast cancer by mammography and if so, whether they had had a screening mammography ever during their life, and if so the number of mammographies and the time intervals between them. Women who never had heard of early detection of breast cancer by mammography $(\mathrm{n}=19 ; 3.4 \%)$ were included in our calculations and counted as 'never screened'. Besides this screening-specific information, sociodemographic variables also were collected (age, marital status, residence, education, and income).

Data were analyzed according to 10-year age groups, and frequency of mammography was analyzed per time intervals in years between mammographies $(4+/ \leq 2,2-3 / \leq 2,>1 />2,1 /$ ever, not specified, never had). Frequencies und confidence limits were calculated in SAS [9]. Statistics comprised the exact Fisher tests of differences in prevalence between the 1995 and the 2005 survey. No correction for multiple testing was applied.

\section{Results}

From 552 women aged 40-79 years, 96.6\% $(\mathrm{n}=533)$ knew about early detection of breast cancer in asymptomatic women by screening mammography (40-49 years: $97.6 \%$, 50-59 years: $96.8 \%, 60-69$ years: $96.9 \%, 70-79$ years: $92.85 \%$ ). Regarding the other sociodemographic variables, no relevant differences in the proportions of women who did know and who did not know about screening were found (data not shown). From the 552 women who knew about early detection, $81.9 \%(n=451)$ were screened at least once.

Table 1 gives the prevalence and 95\% confidence intervals (95\% CI) of self-reported opportunistic screening mammography by age and by number of mammographies per time interval between mammographies and of women who never participated. The comparison of opportunistic screening prevalence in 2005 to 1995 yields several significant increases. Overall, as well as per single age group, the percentage of women who ever had an opportunistic screening mammography increased significantly. The percentage of women who reported to have had 4 or more mammographies within the recommended time interval of two years increased significantly overall as well as per age group, except in the age group 70-79 years, where the prevalence also doubled, but statistically nonsignificant. In the category of 'not specified' (women who were not able to recall the number of mammographies and/or the time interval between mammographies) the percentage increased significantly overall, as well as in all age groups, except in the age group 40-49 years; here the prevalence also more than doubled, but statistically nonsignificant.

\section{Discussion}

Breast cancer screening has been offered to Austrian women since 1974 free of charge and opportunistically, i.e. free choice of radiologist, possibility of additional clinical tests, but no invitation system and no information about women who do not participate.

Austrian women are well informed about early detection of asymptomatic breast cancer by opportunistic screening mammography. The prevalence of knowledge is at about $97 \%$ in women aged $40-69$ years and close to $93 \%$ in women between 70 and 79 years of age. This high level of knowledge results in a high utilization of this service. Compared to the 1995 survey [4], the number of women who reported to have had an opportunistic screening mammography at least once in their life increased significantly (table 1), driven mainly by the increase in the $4+/ \leq 2$ category (= women who had at least 4 mammographies within the recommended time interval of 2 years). This category of women can be regarded to be well screened, albeit the women aged 40-49 years even may be regarded to be overscreened. The reason for this may lie in the fact that mass media frequently report of the necessity to start screening at age 40. This approach is recommended by the Austrian Cancer Society and by various national medical societies and is not completely in accordance with international guidelines [5].

The significant increase over time in the category 'not specified' can at least partly be explained by recall bias. We suppose that in this category many well-screened women are included, however, they were not able to give a precise answer 


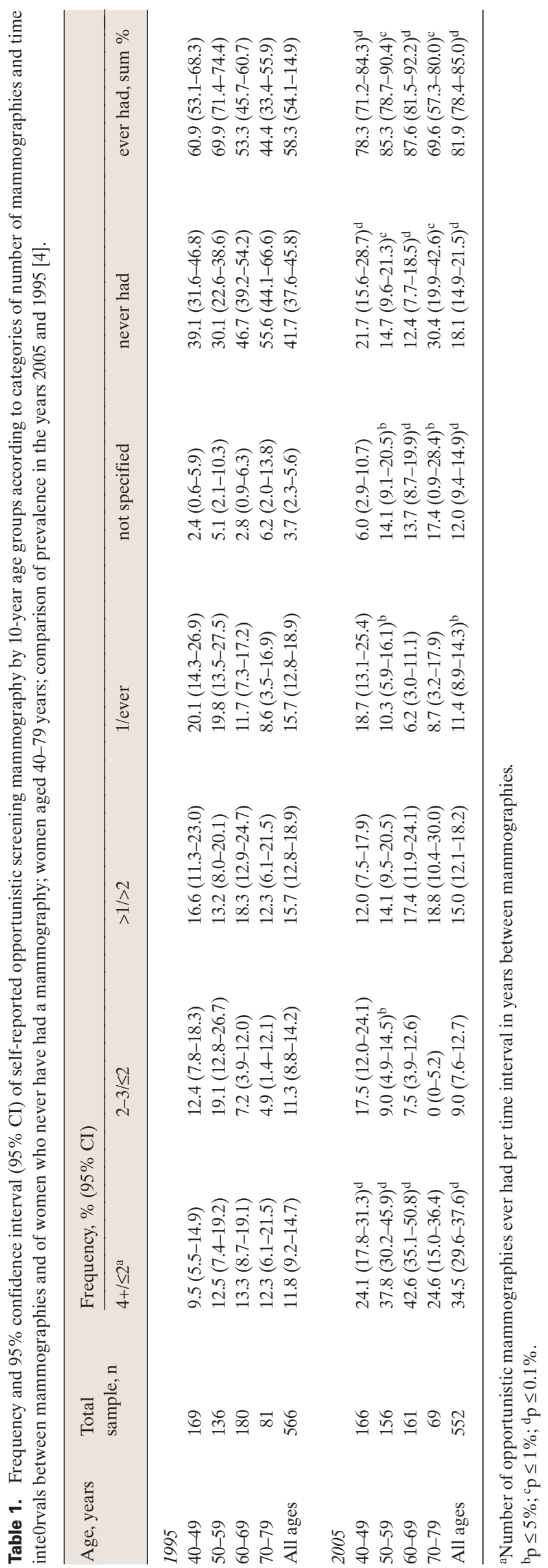

Self-Reported Opportunistic Screening Mammography in Austria on the number of and the exact time intervals between mammographies.

Our results (the 1995 and the 2005 survey) are based on selfreports and could be subject to reporting error. Validation studies showed that women tend to overestimate the usage of screening mammography, especially in low-income populations $[9,10]$. For data protection reasons we were not able to incorporate a validation study into the nationwide survey. Estimates of accuracy of women's self-reports found in validation studies range between $74 \%$ [11] and 97\% [12] when compared to medical records. Thus, considering the high prevalence of knowledge about opportunistic screening mammography $-97 \%$ in our sample - our figures should be a good estimate of the opportunistic screening situation in Austria.

Compared to Finland, the Netherlands, the United Kingdom, and Sweden - countries with an organized screening and participation rates of about $80 \%$ of the target population [13-16] - the usage of the opportunistic screening in Austria improved significantly within the past ten years and seems to be highly accepted and regularly claimed by women.

The end point of screening has to be the reduction of breast cancer mortality, preceded by changes in the stage distribution and by a reduction of the absolute rate of advanced cancers [17]. In a previous analysis we were able to show that the absolute rate of advanced tumors decreased significantly in all age groups in Austria [4]. Furthermore, relative survival increased significantly in the 1990s [2]. However, the effects of improved treatment and of screening cannot easily be separated in analyses of official health statistics.

In Austria, the implementation of a controlled breast cancer screening program is under discussion. From an epidemiological point of view, a controlled screening program is state-ofthe-art because it allows to evaluate the effect of screening when planned and implemented correctly. However, concerning the reduction of mortality, our analyses of breast cancer trends in Austria, Finland, and Sweden [18] do not necessarily support the notion that a controlled screening is the sole option. We were able to show that compared to Finland and Sweden, in Austria the annual percent change (APC, \% per year) in mortality and the annual rate change (ARC, n/100,000 per year) of mortality were more prominent: Austria APC -1.99, ARC -0.59; Finland APC -0.67, ARC -0.16; Sweden APC -1.15, ARC -0.28. It is doubtful whether a change would improve the situation significantly. Therefore it is questionable whether a country with an obviously 'functional' opportunistic breast cancer screening should switch to a controlled breast cancer screening program. Moreover, implementing a controlled screening program would mean to deal with a highly 'contaminated' population due to previous opportunistic mammographies. Thus, for years data would not allow a precise measurement of the screening effect. Furthermore, a change to a controlled program would be costly because of the need to build up a centralized administrative organization. From our current point of view, in times of cut re- 
sources, money is better invested into the 'field', meaning improved information of women, enhancement of training, quality assurance of key professionals, and high-standard equipment. In the province of Tyrol this approach has already been carried out successfully and can serve as a model for the rest of Austria [19].

\section{Acknowledgements}

The Austrian Cancer Survey 2005 was funded by the Austrian Cancer Society.

\section{References}

1 Vutuc C, Waldhoer T, Haidinger G: Cancer mortality in Austria: 1970-2002. Wien Klin Wochenschr 2004;116:669-675.

2 Vutuc C, Waldhoer T, Klimont J, et al.: Survival of women with breast cancer in Austria by age, stage and period of diagnosis. Wien Klin Wochenschr 2002;114:438-442.

3 Wenzel C, Schmidinger M, Huber H: Gibt es Fortschritte in der medikamentösen Therapie von $\mathrm{Pa}$ tienten mit Mammakarzinom? Wien Klin Wochenschr 2001;113:306-320.

4 Vutuc C, Haidinger G, Waldhoer T: Prevalence of self-reported screening mammography and impact on breast cancer mortality in Austria. Wien Klin Wochenschr 1998;110:485-490.

5 Andersson I: Breast cancer screening with mammography. Breast Care 2007;2:4-5.

6 Vutuc C, Haidinger G, Waldhoer T, Ahmad F, Breitenecker G: Prevalence of self-reported cervical cancer screening and impact on cervical cancer mortality in Austria. Wien Klin Wochenschr 1999; 111:354-359.
Janda M, Obermair A, Haidinger G, Waldhoer T, Vutuc C: Attitude and knowledge of Austrian women towards breast self examination. J Cancer Educ 2000;15:91-94.

8 Vutuc C, Waldhoer T, Sevelda P, Micksche M, Haidinger G: Self-reported prostate cancer screening in Austria. J Med Screen 2006;13:148-151.

9 SAS Institute Inc.: SAS/STAT User's Guide,Version 8. Cary, NC, SAS Institute Inc., 1999.

10 Montano DE, Phillips WR: Cancer screening by primary care physicians: a comparison of rates obtained from physician self-report, patient survey, and chart audit. Am J Public Health 1995;85: 795-800.

11 Paskett ED, Tatum CM, Mack DW, Hoen H, Case LD, Velez R: Validation of self-reported breast and cervical cancer screening tests among low-income minority women. Cancer Epidemiol Biomarkers Prev 1996;5:721-726.

12 King ES, Rimer BK, Trock B, Balshem A, Engstrom P: How valid are mammography selfreports? Am J Public Health 1990;80:1386-1388.
13 Olsson S, Andersson I, Karlberg I, et al.: Implementation of service screening with mammography in Sweden: from pilot study to nationwide programme. J Med Screen 2000;7:14-18.

14 Anttila A, Koskela J, Hakama M: Programme sensitivity and effectiveness of mammography service screening in Helsinki, Finland. J Med Screen 2002; 9:153-158.

15 Sinnatamby R, Britton PD: Breast screening in the UK - a national quality assured programme. Breast Care 2007;2:6-10.

16 Holland R, Rijken H, Hendriks J: The Dutch population-based mammography screening: 30-year experience. Breast Care 2007;2:12-18.

17 Day NE, Williams DRR, Khaw KT: Breast cancer screening programmes: the development of a monitoring and evaluation system. Br J Cancer 1989;59: 954-958.

18 Vutuc C, Waldhoer T, Haidinger G: Breast cancer trends: opportunistic screening in Austria versus controlled screening in Finland and Sweden. Eur J Cancer Prev 2006;15:343-346.

19 Frede TE: Opportunistic breast cancer early detection in Tyrol, Austria 1996-2004. Is a mammography-screening program necessary? Eur J Radio 2005;55:130-138. 